\title{
Mitochondrial and Oxidative Unbalance in Placentas from Mothers with SARS-CoV-2 Infection
}

\author{
Chiara Mandò ${ }^{1, *(\mathbb{D})}$, Valeria M. Savasi ${ }^{1,2}{ }^{\mathbb{D}}$, Gaia M. Anelli ${ }^{1} \mathbb{D}$, Silvia Corti ${ }^{2}$, Anaïs Serati ${ }^{1,3} \mathbb{D}^{\mathbb{D}}$, Fabrizia Lisso $^{1} \mathbb{D}^{\mathbb{D}}$, \\ Chiara Tasca ${ }^{4}$, Chiara Novielli ${ }^{1}$ (D) and Irene Cetin ${ }^{1,4}$ (D)
}

1 Department of Biomedical and Clinical Sciences Luigi Sacco, Università degli Studi di Milano, 20157 Milano, Italy; valeria.savasi@unimi.it (V.M.S.); gaia.anelli@unimi.it (G.M.A.); anais.serati@unimi.it (A.S.); fabrizia.lisso@unimi.it (F.L.); chiara.novielli@unimi.it (C.N.); irene.cetin@unimi.it (I.C.)

2 Unit of Obstetrics and Gynecology, Luigi Sacco Hospital, ASST Fatebenefratelli-Sacco, 20157 Milano, Italy; silviacorti871@gmail.com

3 Department of Pathophysiology and Transplantation, Università degli Studi di Milano, 20090 Milano, Italy

4 Department of Obstetrics and Gynecology, Vittore Buzzi Hospital, ASST Fatebenefratelli-Sacco, 20154 Milano, Italy; chiaratasca92@gmail.com

* Correspondence: chiara.mando@unimi.it; Tel.: +39-0250-319-882

check for updates

Citation: Mandò, C.; Savasi, V.M.; Anelli, G.M.; Corti, S.; Serati, A.; Lisso, F.; Tasca, C.; Novielli, C.; Cetin, I. Mitochondrial and Oxidative Unbalance in Placentas from Mothers with SARS-CoV-2

Infection. Antioxidants 2021, 10, 1517.

https://doi.org/10.3390/antiox10101517

Academic Editors: Carmen

M. Vázquez and Luis Sobrevia

Received: 19 August 2021

Accepted: 21 September 2021

Published: 24 September 2021

Publisher's Note: MDPI stays neutral with regard to jurisdictional claims in published maps and institutional affiliations.

Copyright: (C) 2021 by the authors Licensee MDPI, Basel, Switzerland. This article is an open access article distributed under the terms and conditions of the Creative Commons Attribution (CC BY) license (https:// creativecommons.org/licenses/by/ $4.0 /)$

\begin{abstract}
SARS-CoV-2 infection has been related to adverse pregnancy outcomes. A placental role in protecting the fetus from SARS-CoV-2 infection has been documented. Nevertheless, it is still unclear how the placenta is affected in SARS-CoV-2 infection. Here we assessed placental mitochondrial (mt) and oxidative features in COVID-19 and healthy mothers. mtDNA levels, DNA oxidative damage, expression levels of genes involved in antioxidant defenses, mitochondrial dynamics and respiratory chain subunits were investigated in placentas from singleton pregnancies of 30 women with SARS-CoV-2 infection during the third trimester (12 asymptomatic, 18 symptomatic) and 16 controls. mtDNA levels decreased in COVID-19 placentas vs. controls and inversely correlated with DNA oxidative damage, which increased in the symptomatic group. Antioxidant gene expressions decreased in SARS-CoV-2 mothers (CAT, GSS). Symptomatic cases also showed a lower expression of respiratory chain (NDUFA9, SDHA, COX4I1) and mt dynamics (DNM1L, FIS1) genes. Alterations in placental mitochondrial features and oxidative balance in COVID-19-affected mothers might be due to the impaired intrauterine environment, generated by systemic viral effects, leading to a negative vicious circle that worsens placental oxidative stress and mitochondrial efficiency. This likely causes cell homeostasis dysregulations, raising the potential of possible long-term effects.
\end{abstract}

Keywords: pregnancy; SARS-CoV-2; COVID-19; placenta; mitochondria; oxidative stress

\section{Introduction}

The 2019 coronavirus disease (COVID-19), caused by severe acute respiratory syndrome coronavirus 2 (SARS-CoV-2), has been related to adverse pregnancy outcomes such as preterm birth, premature rupture of membranes, low birth weight and high neonatal intensive care unit admission [1-5]. It is well recognized that these conditions can drive negative long-term consequences, cardiovascular and metabolic diseases that can reach far into the future life of the adult [6]. Therefore, the need for a deeper understanding of in utero processes in mothers affected by COVID-19 has become urgent and essential for the proper management of these pregnancies [5].

The placenta is a metabolically active barrier that forms in utero, mediates fetal oxygenation and nutrition and protects the fetus from pathogens by activating different molecular pathways [7]. Recently, a placental role in fetal protection from SARS-CoV-2 infection has been suggested [7,8]. At the same time, evidence for vertical transmission of SARS-CoV-2 from the mother to the fetus has been documented in a small but significant percentage of cases [9-11]. Although histopathologic abnormalities, such as maternal 
vascular malperfusion (MVM), inflammation and fibrinoid deposition have been described in some studies [7,12-15], we recently showed that SARS-CoV-2 infection during the third trimester does not influence placental histological pattern when compared to appropriately matched controls [16]. It is therefore unclear how the placenta is affected in SARS-CoV-2 infection, depending also on timing and duration of exposure.

Dysfunctional placentas may lead to altered oxygenation in different pregnancy pathologies, such as IUGR [17], maternal obesity and gestational diabetes mellitus [18]. This is accompanied by altered mitochondrial features [19,20], accounting for an oxidative impairment in the placental and intrauterine environment. Indeed, mitochondria have a key role in the maintenance of cellular homeostasis and are the energy powerhouse of the cell, driving placental functions and efficiency. Interestingly, COVID-19 has been associated with acute inflammatory processes, redox imbalance, oxidative stress and altered mitochondrial dynamics [21-24]. However, to date, no data have been reported on placental tissue.

The aim of the present study was to assess the mitochondrial and oxidative features of placentas from mothers affected by COVID-19 during the third trimester of pregnancy compared to healthy control pregnancies. This will allow light to be shed on the possible role of oxidative stress and inflammatory processes characterizing SARS-CoV-2 infection on placental mitochondrial balance, with possible short- or long-term consequences.

\section{Materials and Methods}

\subsection{Population}

Pregnant women were prospectively enrolled between March and July 2020 from the Obstetrics and Gynecology Units of University Hospitals of the ASST Fatebenefratelli-Sacco in Milan. COVID cases were enrolled in the Regional Hub for COVID-19 patients at the "L. Sacco" Hospital and controls at the "V. Buzzi" Children Hospital.

The study was conducted in accordance with the Declaration of Helsinki and in compliance with all current Good Clinical Practice guidelines, local laws, regulations and organizations. The protocol was approved by the Hospital Ethical Committee (Comitato Etico Milano Area 1, protocol n ${ }^{\circ} 15408,11$ March 2020). All participants gave their informed consent to collect personal data and biological samples.

Only women with singleton pregnancies who delivered at term or very late preterm (>36 gestational weeks) were included. Placentas from 30 women with a confirmed SARSCoV-2 infection during the third trimester of pregnancy were collected and compared to 16 control healthy pregnancies. The controls were women with no maternal or fetal pathologies and normal pregnancy outcomes.

Diagnosis of maternal SARS-CoV-2 infection was performed by a positive result on a reverse transcriptase polymerase chain reaction (PCR) assay of a maternal nasopharyngeal swab specimen. The swab samples were processed with the automated ELITe InGenius system and the GeneFinder COVID-19 Plus RealAmp Kit assay, according to the manufacturer's instructions (ELITechGroup, Inc., Bothell, WA, USA) [25]. This assay targets three genes: RNA-dependent RNA polymerase, nucleocapsid protein and envelope membrane protein, with high specificity. The test results were obtained within $24 \mathrm{~h}$.

The presence of the SARS-CoV-2 infection was also evaluated in placentas, after fixation with formalin, by detecting the viral RNA by PCR. Total RNA was extracted from 3 unstained slides ( $5 \mu \mathrm{m}$ thick) using Quick-RNA FFPE Miniprep (Zymo Research, Irvine, CA, USA) in an elution volume of $30 \mu \mathrm{L}$. The WHO/Charité SARS-CoV-2 RealTime RT-PCR E-gene assay (Berlin, Germany) was adapted using a qPCRBIO Probe 1-Step Go Master Mix (PCR Biosystems). Human RNase P was used as an internal control to confirm that the RNA was adequately extracted and conserved. Positive samples were confirmed using the CE-IVD Logix Smart COVID-19 kit (Co-Diagnostic, Salt Lake City, UT, USA). According to the literature, cycle threshold values less than 40 were considered positive. The positivity to SARS-CoV-2 viral infection was established by two consecutive and positive PCR experiments. 
COVID-19 cases were divided into asymptomatic $(n=12$, with no symptoms and negative imaging when performed) and symptomatic $(n=18)$ cases. The symptomatic cases included 3 women with $\mathrm{SaO}_{2} \leq 94 \%$, who required respiratory support.

Maternal, obstetrical and neonatal data were collected from both cases and controls.

Neonatal weight was normalized for gestational age by calculating the $Z$-score, as previously described [26]. Briefly, for each neonate, the Z-score of birth weight was calculated as: $[y(t)-\mu(t)] / \sigma(t)$, where $y(t)$ is the birth weight and $\mu(t)$ and $\sigma(t)$ are the mean and standard deviation of the reference at gestational age, $t$ [27].

\subsection{Placental Collection and Molecular Analysis}

Placentas were collected in sterile conditions immediately after delivery, and chorionic villi biopsies $\left(1 \mathrm{~cm}^{3}\right)$ were sampled from different sites of the placental disc (central, median and peripheral) from the maternal side. Maternal decidua was carefully peeled off the maternal side of the placenta and the villous portion of the tissue was picked up by coring $1 \mathrm{~cm}^{3}$ biopsies. Then the samples were washed with physiological solution to eliminate excessive blood and either immediately frozen in liquid nitrogen for mtDNA and DNA oxidative damage analysis or included in RLT lysis buffer (Qiagen, Hilden, Germany) and stored at $-80^{\circ} \mathrm{C}$ for gene expression analysis.

\subsection{Mitochondrial DNA (mtDNA) Levels}

Total DNA was isolated from placental tissue $(\sim 25 \mathrm{mg})$ with the spin column-based DNeasy Blood \& Tissue kit (Qiagen) and its concentration measured by a NanoDrop ND-1000 spectrophotometer (NanoDrop Technologies, Wilmington, DE, USA).

mtDNA content was assessed by real-time PCR normalizing the levels of a nonpolymorphic mitochondrial gene $(C y$ tochrome $\beta)$ to those of a single-copy nuclear gene (RNase P) [28]. Total DNA (30 ng) was analyzed in triplicate on the 7500 Fast Real-Time PCR system by using TaqMan chemistry (MT-CYB: Hs02596867_s1 and RNase P: 4316844; Thermo Fisher Scientific, Carlsbad, CA, USA). Cq values with standard deviation $\geq 0.25$

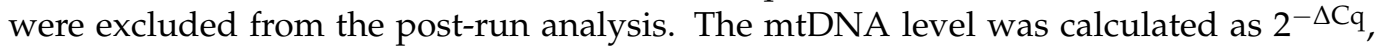
obtained after subtracting the RNase $P$ average $C q$ value from the Cytochrome $B$ average $C q$ value $(\Delta \mathrm{Cq})$.

\subsection{DNA Oxidative Damage}

The DNA oxidative damage in placental tissue was measured by the DNA/RNA Oxidative Damage (High Sensitivity) ELISA Kit (Cayman Chemical, Ann Arbor, MI, USA). This competitive ELISA covers three oxidized guanine species as markers for DNA/RNA oxidative damage: 8-hydroxy-2'-deoxyguanosine (8-OH-dG) from DNA, 8hydroxyguanosine from RNA and 8-hydroxyguanine (8-OHG) from either DNA or RNA.

The previously isolated total DNA (specifically, $4.128 \mu \mathrm{g}$ in Elution Buffer-AE) was denatured by heating at $97^{\circ} \mathrm{C}$ for $7^{\prime}$, then placed on ice. Denatured DNA was digested with 2.5 units of Nuclease P1 (Product Number N8630) in $\mathrm{ZnCl}_{2}$ Buffer (0.1 mM, pH 5.2) (1 h $45^{\prime}$ at $37^{\circ} \mathrm{C}$ ), according to the product information sheet. Samples were then dephosphorylated by 1 unit of Alkaline Phosphatase from calf intestine (CIP enzyme, Product Number P4978) in 1X CIP Reaction Buffer ( $\mathrm{pH} 7.5-8.5,1 \mathrm{~h}$ at $37^{\circ} \mathrm{C}$ ) and inactivated with $5 \mathrm{mM}$ EDTA (10' at $75^{\circ} \mathrm{C}$ ). Enzymatic digestion reagents were purchased from Sigma-Aldrich (Saint Louis, MN, USA).

Treated DNA samples were then assayed for the ELISA experiment, following the manufacturer's instructions (Product Number 589320). Samples were diluted 1:10 and analyzed in duplicate. The plate was spectrophotometrically detected at $415 \mathrm{~nm}$, and an 8-point standard curve was used for concentration determination. Calculations were performed using the online spreadsheet for data analysis supplied by the manufacturer (https:/ / www.myassays.com/8-hydroxy-2-deoxy-guanosine.assay, by Cayman Chemical, accessed on 25 September 2020). 


\subsection{Gene Expression Analysis}

In 24 samples, placental tissue biopsies $(\sim 30 \mathrm{mg})$ were mechanically shredded in $600 \mu \mathrm{L}$ of RLT Buffer (Qiagen) added with DiThioThreitol (20 uL of 2M DTT per $1 \mathrm{~mL}$ RLT) with a Potter homogenizer, for lysing the tissue prior to RNA isolation. Total RNA was extracted from the tissue homogenate using the column-based RNeasy Mini Kit (Product Number 74,106-Qiagen) following the manufacturer's instructions.

RNA concentration was then quantified by NanoDrop ND-1000.

After DNase I treatment (Turbo DNase; Thermo Fisher Scientific, Vilnius, Lithuania), aiming to remove potentially contaminating DNA, total RNA was reverse transcribed by using the High Capacity cDNA Reverse Transcription Kit (Thermo Fisher Scientific) with random examers.

A triplicate cDNA analysis was performed for:

- 4 genes related to antioxidant defenses_Catalase (CAT, assay ID: Hs00156308_m1), SuperOxide Dismutase 1 (SOD1, assay ID: Hs00533490_m1), Glutathione SynthetaSe (GSS, assay ID: Hs00609286_m1) and Glutathione ReductaSe (GSR, assay ID: Hs00167317_m1);

- 4 genes belonging to the respiratory chain subunits, within the inner membrane of mitochondria-NADH-dehydrogenase-1 $\alpha$ subcomplex 9 (NDUFA9, complex I; assay ID: Hs00245308_m1), Succinate DeHydrogenAse complex subunit A (SDHA, complex II; assay ID: Hs00188166_m1), UbiQuinol-Cytochrome C Reductase core protein I (UQCRC1, complex III; assay ID: Hs00163415_m1) and Cytochrome C Oxidase subunit IV Isoform 1 (COX4I1, complex IV; assay ID: Hs00971639_m1);

- 3 genes related to the mitochondrial dynamics of fission and fusion-DyNaMin-1-Like Protein 1 (DNM1L, assay ID: Hs01552605_m1), mitochondrial FISsion 1 Protein (FIS1, assay ID: Hs00211420_m1) and mitochondrial dynamin-like GTPase (OPA1, assay ID: Hs01047013_m1).

The relative gene expressions of the above-listed genes were determined by 7500 Fast Real-Time PCR with TaqMan assays, according to the $2^{-\Delta \Delta \mathrm{Cq}}$ method [29] relative to Ribosomal Protein L13A (RPL13A, assay ID: Hs04194366_g1) selected from a pool of placental endogenous genes. Indeed, RPL13A shows a minimal placental site-to-site expression variability [30].

The reagents were supplied by Life Technologies (Thermo Fisher Scientific, Foster City, CA, USA).

Only Cq values with a standard deviation $\leq 0.25$ across triplicates were included in the analysis.

\subsection{Statistical Analysis}

All data sets underwent the Kolmogorov-Smirnov test for the assessment of scores distribution.

When data presented normal distribution, the parametric one-way ANOVA with Tukey's HSD post-hoc test was applied, with Levene's test for homogeneity of variances. When data did not present normal distribution, the non-parametric Kruskal-Wallis test was performed, with the Mann-Whitney $U$ test used for a post-hoc analysis when significant results were obtained.

A chi-squared test for independence with Yates Continuity Correction was applied to determine whether the results in the control and pathological samples, with or without symptoms, were related to the categorical variables: type of delivery (vaginal delivery, cesarean section), geographic origin (Caucasian, non-Caucasian), pregestational BMI (underweight, normal weight, overweight, obese), fetal sex (female, male), maternal smoking (yes/no). By using the chi-squared test, the observed frequencies of cases that occurred in each of the categories were therefore compared with the values that would have been expected if there was no association between the two variables being measured.

The relationships between variables were investigated using the non-parametric Spearman's Rank Order Correlation (rho).

Differences and correlations were considered significant when $p<0.05$. 
Analyses were performed using the statistical package SPSS, v.27 (IBM; Armonk, NY, USA).

\section{Results}

\subsection{Characteristics of the Population}

Table 1 shows the clinical characteristics of the population.

Table 1. Clinical characteristics of the population. Values are presented as mean \pm standard deviation. BMI: Body mass index; CS: cesarean section; UA: umbilical artery.

\begin{tabular}{cccc}
\hline & $\begin{array}{c}\text { Controls } \\
(\boldsymbol{n}=\mathbf{1 6})\end{array}$ & $\begin{array}{c}\text { Asymptomatic } \\
\text { COVID-19 }(\boldsymbol{n}=\mathbf{1 2})\end{array}$ & $\begin{array}{c}\text { Symptomatic } \\
\text { COVID-19 }(\boldsymbol{n}=\mathbf{1 8})\end{array}$ \\
\hline Pregestational BMI $\left(\mathrm{Kg} / \mathrm{m}^{2}\right)$ & $23.2 \pm 3.4$ & $23.8 \pm 5.1$ & $25.4 \pm 4.5$ \\
Gestational weight gain $(\mathrm{Kg})$ & $12.8 \pm 3.5$ & $13.2 \pm 5.3$ & $11.1 \pm 4.1$ \\
Maternal age (years) & $32.9 \pm 4.9$ & $32.2 \pm 3.8$ & $31.8 \pm 6.0$ \\
Maternal hematocrit & $33.7 \pm 3.1$ & $34.5 \pm 2.4$ & $33.9 \pm 3.1$ \\
Maternal hemoglobin (mg/dL) & $11.4 \pm 1.2$ & $11.7 \pm 1.0$ & $11.4 \pm 1.5$ \\
Maternal geographic origin & $69 \%$ & $80 \%$ & $63 \%$ \\
$\quad$ (\% Caucasian) & & & \\
Maternal smoking & 0 & 0 & 1 \\
(n. of smokers) & $31 \%$ & $30 \%$ & $38.9 \pm 1.4$ \\
Mode of delivery (\% CS) & $39.9 \pm 1.1$ & $39.1 \pm 1.4$ & $3239 \pm 395$ \\
Gestational age (weeks) & $3487 \pm 298$ & $3257 \pm 416$ & $0.015 \pm 1.17$ \\
Birth weight (g) & $0.24 \pm 0.81$ & $-0.05 \pm 1.15$ & $47.4 \%$ \\
Birth weight (Z-score) & $50.0 \%$ & $30.0 \%$ & $7.32 \pm 0.08$ \\
Fetal sex (\% males) & $7.30 \pm 0.09$ & $7.36 \pm 0.08$ & \\
UA pH & & &
\end{tabular}

No significant differences were observed among the study groups, both for the continuous (one-way ANOVA) and the categorical variables (chi-squared test for independence with Yates Continuity Correction).

Table 2 reports the therapy and clinical history of the SARS-CoV-2-positive patients. The antiviral therapy was composed of Ritonavir + Lopinavir. Few patients delivered the same day they received a COVID-19 diagnosis; therefore, they did not receive a specific antepartum therapy.

Table 2. Therapy and clinical history of the SARS-CoV-2-positive patients. NPS: nasopharyngeal swab. SD: standard deviation.

\begin{tabular}{ccc}
\hline & $\begin{array}{c}\text { Asymptomatic } \\
\text { COVID-19 }(n=12)\end{array}$ & $\begin{array}{c}\text { Symptomatic } \\
\text { COVID-19 }(n=18)\end{array}$ \\
\hline Antepartum therapy & & \\
Antiviral (\%) & $8 \%$ & $44 \%$ \\
Oxygen support (\%) & $0 \%$ & $22 \%$ \\
Days between a positive NPS and delivery & $1.5 \pm 3.4$ & $5.4 \pm 9.6$ \\
(mean \pm SD) & & \\
Vital signs & $0 \%$ & $44 \%$ \\
Fever $\geq 37^{\circ} \mathrm{C}(\%)$ & $8 \%$ & $39 \%$ \\
Respiratory rate $\geq 20(\%)$ & $0 \%$ & $22 \%$ \\
Heart rate $\geq 100 \mathrm{bpm}(\%)$ & & \\
\hline
\end{tabular}

Three of the thirty placentas from SARS-CoV-2-infected mothers were also positive when tested for the virus (one from an asymptomatic mother and two from symptomatic mothers).

However, the clinical and molecular data from the three COVID-19-positive placentas were similar to the average of their group. 


\subsection{Molecular Analyses}

The non-parametric Kruskal-Wallis test was performed to assess the differences among the three groups (controls, asymptomatic COVID-19, symptomatic COVID-19).

\subsection{1. mtDNA and DNA Oxidative Damage}

The placental mtDNA levels were significantly different among groups $(p<0.01)$. Specifically, the Mann-Whitney U test showed significantly lower levels in the placentas from both COVID-19 groups compared to the controls ( $p<0.01$, in both cases) (Figure 1A).
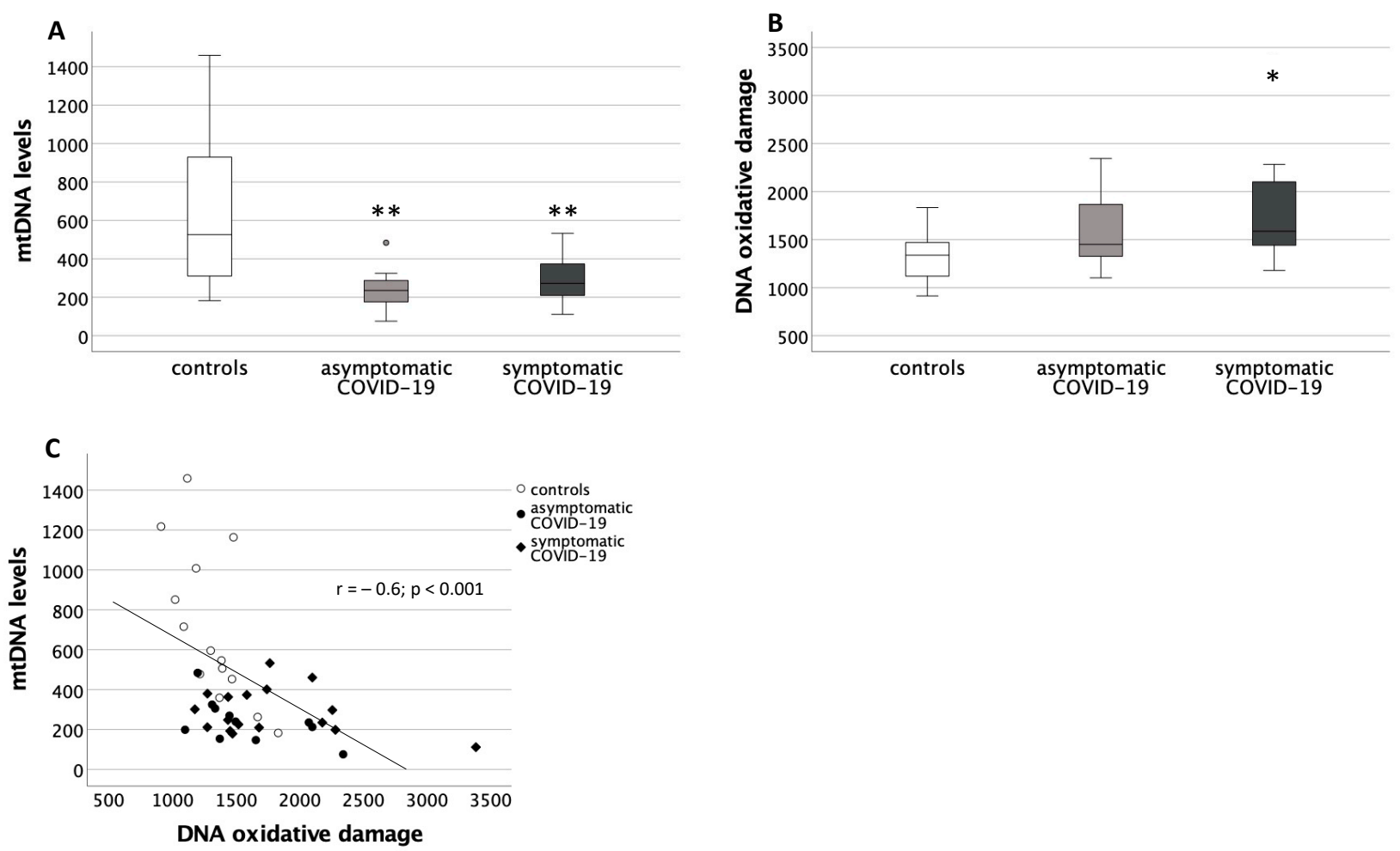

Figure 1. Mitochondrial DNA (mtDNA) and DNA oxidative damage levels in placentas from healthy control pregnancies and mothers infected with SARS-CoV-2 during the third trimester of pregnancy. (A) Placental mtDNA levels. Data are shown as box plots, indicating the median and the 25th and 75th percentiles. Data were significantly different among the three groups (Kruskal-Wallis test, $p<0.01$ ). ${ }^{* *} p<0.01$ vs. controls (Mann-Whitney U test), round circles are values that differ of more than 2 standard deviations from the median value. (B) Placental DNA oxidative damage levels. Data are shown as box plots, indicating the median and the 25th and 75th percentiles. Data were significantly different among the three groups (Kruskal-Wallis test, $p<0.05$ ). ${ }^{*} p<0.05$ vs. controls (Mann-Whitney U test). (C) Correlation between placental DNA oxidative damage and mtDNA levels. White circles: controls; black circles: asymptomatic COVID-19; black diamonds: symptomatic COVID-19.

The DNA oxidative damage was also significantly different among groups $(p<0.05)$, with placentas from the symptomatic COVID-19 group showing increased damage compared to the controls $(p<0.05)$ (Figure 1B).

Interestingly, a significant negative correlation was found between the placental mtDNA levels and the DNA oxidative damage levels $(r=-0.6 ; p<0.001)$ (Figure 1C).

\subsubsection{Expression of Genes Related to Oxidative Defenses}

The gene expression of four antioxidant genes was measured: CAT, SOD1, GSS and GSR.

CAT placental levels were significantly different among groups $(p<0.05)$, with both COVID-19 groups showing a significant decrease in the post-hoc analysis, compared to controls (asymptomatic: $p=0.03$; symptomatic: $p=0.02$ ) (Figure 2A). 

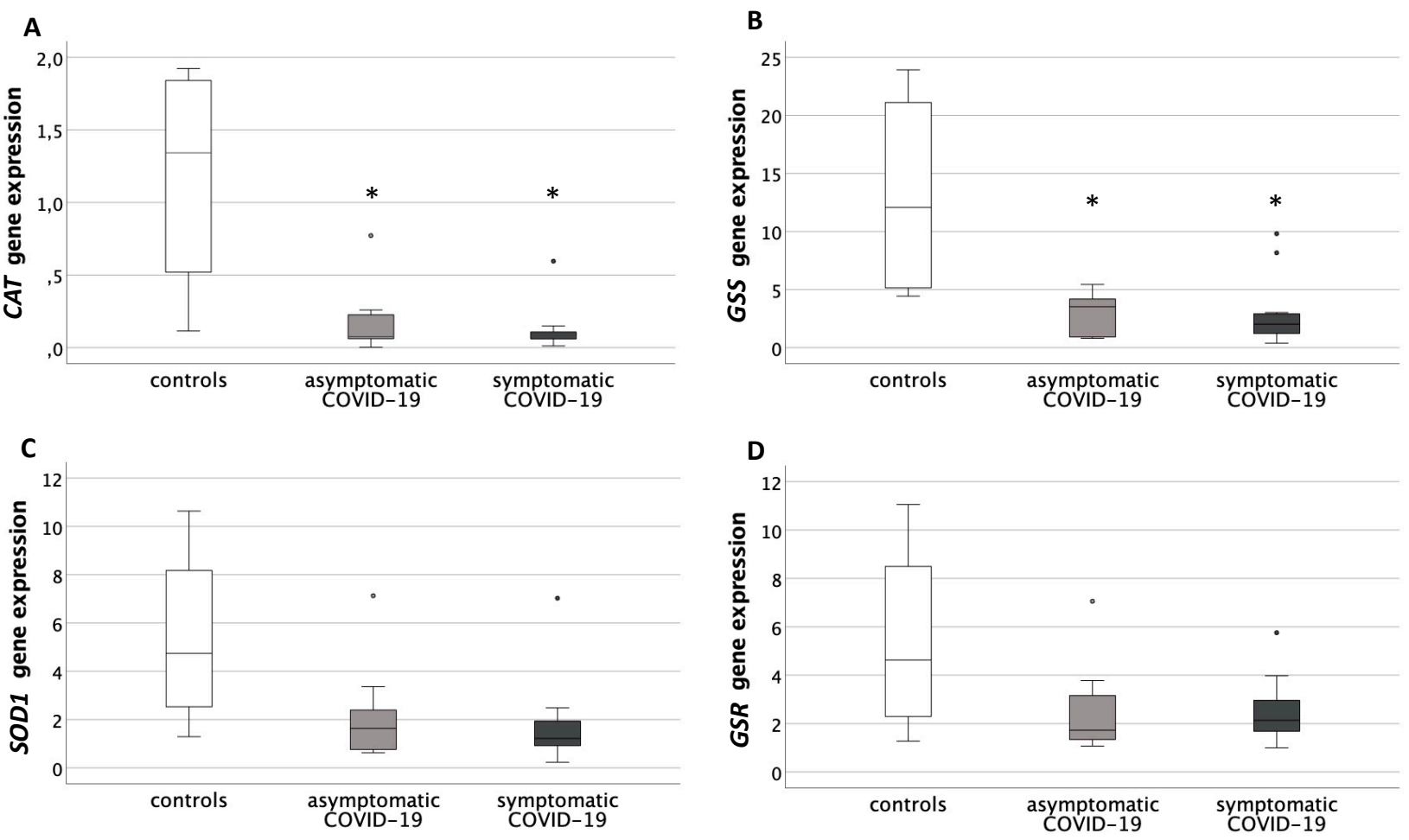

Figure 2. Expression levels of genes related to antioxidant defenses in placentas from healthy control pregnancies and mothers infected with SARS-CoV-2 during the third trimester of pregnancy. (A) Placental Catalase (CAT) gene expression levels. Data were significantly different among the three groups (Kruskal-Wallis test, $p<0.05$ ). ${ }^{*} p<0.05$ vs. controls (Mann-Whitney U test). (B) Placental Glutathione SynthetaSe (GSS) expression levels. Data were significantly different among the three groups (Kruskal-Wallis test, $p<0.05$ ). ${ }^{*} p<0.05$ vs. controls (Mann-Whitney U test). (C) Placental SuperOxide Dismutase $(S O D)$ gene expression levels. Data were not significantly different among the three groups. (D) Placental Glutathione ReductaSe (GSR) gene expression levels. Data were not significantly different among the three groups. Round circles are values that differ of more than 2 standard deviations from the median value.

GSS expression was also significantly different among the three study groups $(p<0.05)$. The post-hoc analysis reported significantly decreased levels in asymptomatic COVID-19 placentas $(p=0.03)$ and in symptomatic COVID-19 placentas vs. controls $(p=0.02)$ (Figure 2B).

SOD1 and GSR showed decreased levels of gene expression in the placentas of both COVID-19 groups compared to controls, though not significantly (Figure 2C,D).

\subsubsection{Expression of Genes Belonging to the Respiratory Chain Subunits}

The gene expression of four genes belonging to the respiratory chain subunits was measured: NDUFA9, SDHA, UQCRQ1 and COX4I1.

NDUFA9, SDHA and COX4I1 presented a significantly different gene expression among groups ( $p<0.05$, for all genes). The Mann-Whitney $U$ test showed significantly decreased levels in symptomatic COVID-19 compared to controls (NDUFA9: $p=0.04$; SDHA: $p=0.01$; COX4I1: $p=0.01$ ) (Figure 3A-C). 
A

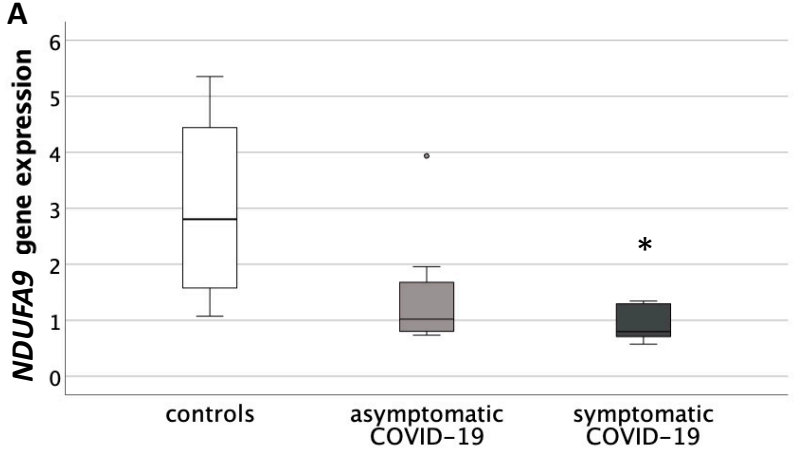

C

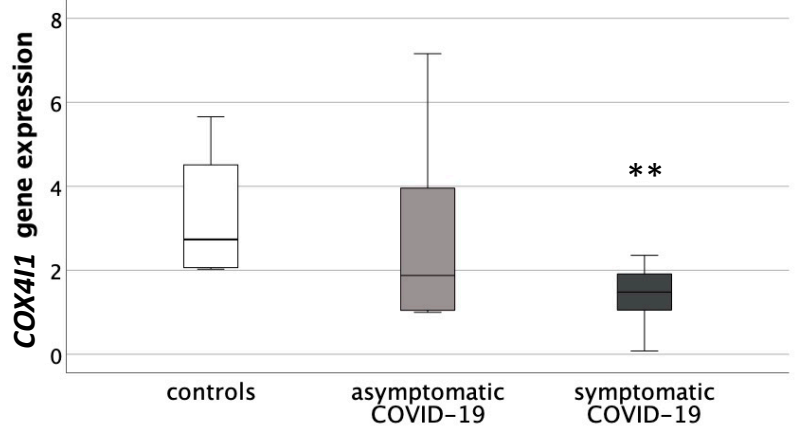

B

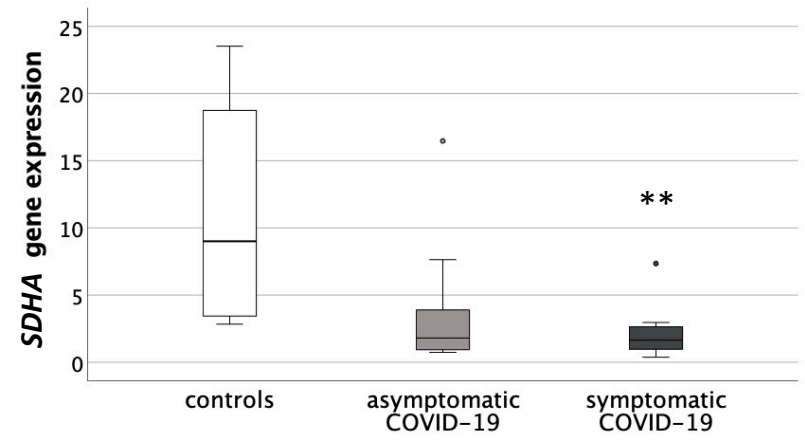

D

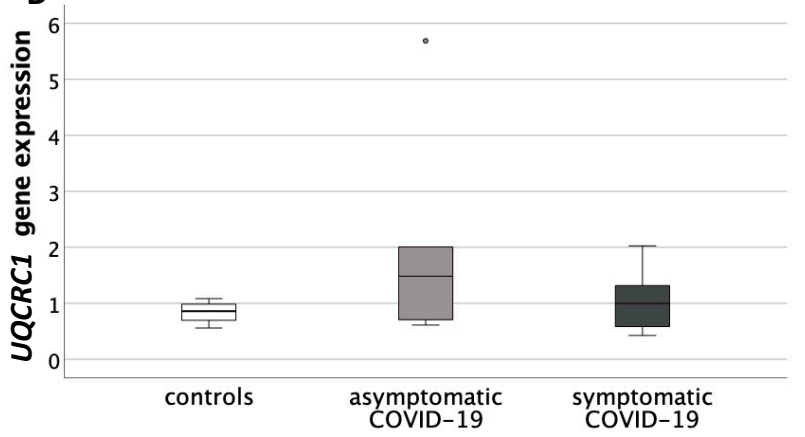

Figure 3. Expression levels of genes belonging to the respiratory chain subunits, within the inner membrane of mitochondria, in placentas from healthy control pregnancies and mothers infected with SARS-CoV-2 during the third trimester of pregnancy. (A) Placental NADH-dehydrogenase-1 $\alpha$ subcomplex 9 (NDUFA9, complex I) gene expression levels. Data were significantly different among the three groups (Kruskal-Wallis test, $p<0.05$ ). ${ }^{*} p<0.05$ vs. controls (Mann-Whitney U test). (B) Placental Succinate DeHydrogenase complex subunit A (SDHA, complex II) gene expression levels. Data were significantly different among the three groups (Kruskal-Wallis test, $p<0.05$ ). ${ }^{* *} p=0.01$ vs. controls (Mann-Whitney U test). (C) Placental Cytochrome c OXidase subunit IV Isoform 1 (COX4I1, complex IV) gene expression levels. Data were not significantly different among the three groups. (D) Placental UbiQuinol-Cytochrome c Reductase Core protein I (UQCRC1, complex III) gene expression levels. Data were significantly different among the three groups (Kruskal-Wallis test, $p<0.05$ ). ${ }^{* *} p=0.01$ vs. controls (Mann-Whitney U test). Round circles are values that differ of more than 2 standard deviations from the median value.

UQCRC1 gene expression was not significantly different among groups (Figure 3D).

\subsubsection{Expression of Genes Related to Mitochondrial Dynamics of Fusion and Fission}

Finally, the gene expression levels of three genes involved in the mitochondrial dynamics of fission and fusion were tested: DNM1L, FIS1 and OPA1.

Both DNM1L and FIS1 showed a significant difference in their gene expression levels among groups ( $p<0.05$, for both genes). Post-hoc analysis showed that the symptomatic COVID-19 group had significantly decreased values compared to the controls (DNM1L: $p=0.02$; FIS1: $p=0.01$ ) (Figure 4A,B). 
A

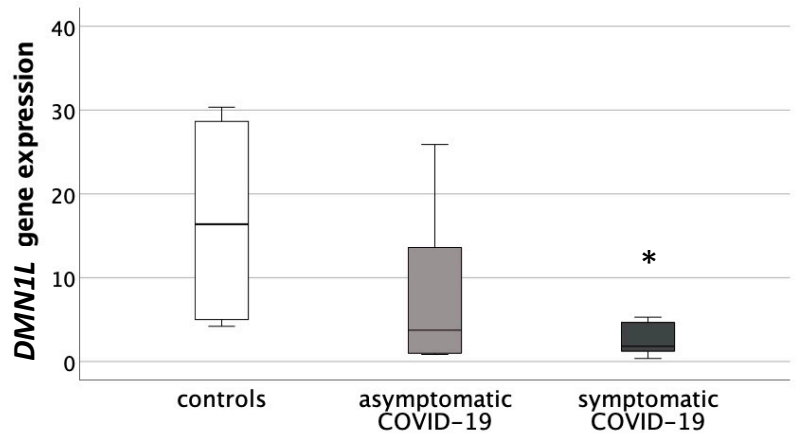

C

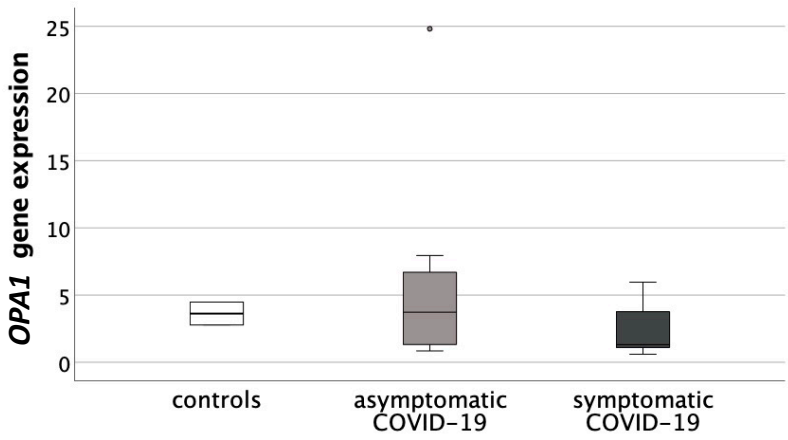

\section{B}

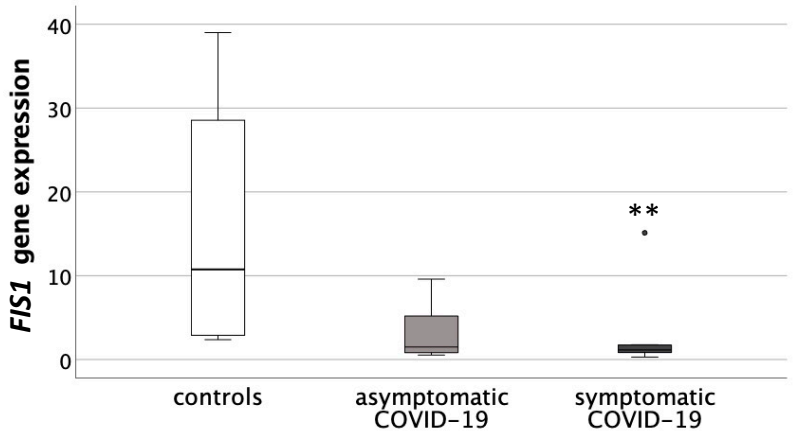

Figure 4. Expression levels of genes related to the mitochondrial dynamics of fusion and fission in placentas from healthy control pregnancies and mothers infected with SARS-CoV-2 during the third trimester of pregnancy. (A) Placental Pro-Fission Dynamin-1-like Protein (DNM1L) gene expression levels. Data were significantly different among the three groups (Kruskal-Wallis test, $p<0.05$ ). ${ }^{*} p<0.05$ vs. controls (Mann-Whitney U test). (B) Placental Fission 1 Protein (FIS1) gene expression levels. Data were significantly different among the three groups (Kruskal-Wallis test, $p<0.05$ ). ${ }^{* *} p=0.01 \mathrm{vs}$. controls (Mann-Whitney U test). (C) Placental Pro-Fusion mitochondrial Dynamin-like GTPase (OPA1) gene expression levels. Data were not significantly different among the three groups. Round circles are values that differ of more than 2 standard deviations from the median value.

OPA1 gene expression was not significantly different among groups (Figure 4C).

No significant correlation was found between gestational age, pregestational BMI, gestational weight gain and maternal age in any of the analyzed molecular data.

\section{Discussion}

To our knowledge, this is the first study exploring the mitochondrial and oxidative balance at the placental level in pregnancies of mothers infected by SARS-CoV-2 during the third trimester of pregnancy.

Alterations of placental genes and proteins involved in inflammatory and oxidative stress conditions have been previously reported in other gestational infections [31-33]. Interestingly, placentas of women after the exacerbation of herpesvirus infection present altered mitochondrial protein expression [34] and mitochondrial fission and fusion are dysregulated in cells affected by most RNA viruses, including Zika, hepatitis B and C, Dengue and Chikungunya [35].

Our preliminary results demonstrate that placental mtDNA levels are significantly decreased in COVID-19-infected pregnant patients, both symptomatic and asymptomatic, compared to controls. mtDNA levels were significantly and inversely related to DNA oxidative damage, a direct measure of cell oxidative stress, which was significantly increased in the most severe (symptomatic) group. Moreover, genes involved in oxidative defenses presented a significantly decreased expression in placentas of asymptomatic SARS-CoV-2infected mothers vs. controls (namely, CAT and GSS). Similarly, COVID-19 symptomatic cases also showed significantly lower expression levels of these genes compared to controls, 
together with a decrease in genes belonging to the mitochondrial respiratory chain subunits (NDUFA9, SDHA, COX4I1) and to mitochondrial dynamics (DNM1L, FIS1).

Oxidative stress is the result of the imbalance between reactive oxygen species (ROS) and antioxidant defenses [36]. It can be generated by increased inflammation, and can also further induce inflammation, in a vicious circle exacerbating the adverse environment. Mitochondria are the major source of ROS in cells. At the same time, increased placental mitochondrial ROS may directly damage mtDNA, thus inhibiting the adaptive biogenesis of mitochondria and reducing respiratory activity [37-39]. This might explain our observations in the placentas of mothers infected by SARS-CoV-2 during the third trimester of pregnancy. Indeed, these placentas presented decreased antioxidant defenses and increased DNA oxidative damage, inversely related to mitochondrial DNA levels, together with decreased expression of genes belonging to the respiratory chain subunits, which also accounts for reduced mitochondrial biogenesis. Compromised antioxidant capacity coupled with oxidative stress may lead to mitochondrial damage, which in turn increases ROS production, resulting in impaired cell function and inability of compensation, thus exacerbating oxidative damage [40]. In placentas of COVID-19 mothers, the acute infection event, oxygen desaturation and placental malperfusion may therefore impede the setting up of compensation mechanisms, leading to altered mitochondrial features and redox unbalance. Similar conditions have been reported in several pregnancy pathologies. Placental oxidative stress and mitochondrial dysfunctions have been reported in a range of gestational disorders, also associated with raised inflammation, such as preeclampsia (PE), intrauterine growth restriction, gestational diabetes and maternal obesity, leading to consequences that can reach far into the future life of the adult [19,20,37,41-45]. In particular, we have previously reported altered mitochondrial function in preeclamptic placentas [46] and increased preeclampsia has been reported in COVID-19 patients [47]. In PE, Holland and colleagues reported decreased placental respiratory reserve capacity, with compensatory antioxidant and mitochondrial responses [48]. These findings support our hypothesis that an altered intrauterine environment characterized by enhanced inflammation and oxidative stress might lead to dysregulations of oxidative and mitochondrial features in COVID-19 placentas, with different alteration levels depending on the degree of severity. Interestingly, in non-pregnant patients, COVID-19 has been reported to provoke redox unbalance and oxidative stress, and SARS-CoV-2 infection has been associated with altered mitochondrial dynamics [21-24]. Moreover, altered circulating mitochondrial DNA has been recently reported as an indicator of severe illness and mortality in non-pregnant patients affected by COVID-19, suggesting mitochondrial dysfunction related to the disease [24].

To date, conflicting data have been reported on the macro- and microscopical morphologies of placental and fetal tissues positive to SARS-CoV-2 [15,49]. A few studies on the pregnancies of mothers affected by COVID-19 have reported increased placental inflammation and widespread abnormalities in the placental vasculature, suggesting poor perfusion and hypoxia, which may result in multiple placental malfunctions $[12,13,50,51]$. However, most of these studies lacked control groups, allowing limited conclusions on placental findings following maternal SARS-CoV-2 infection. Indeed, other studies did not account for fetal or maternal vascular malperfusion [16,52]. In a recent prospective multicenter case-control study, we reported no differences in the placental histological pattern in a cohort of mothers affected by SARS-CoV-2 at the end of pregnancy compared to controls with similar maternal characteristics [16]. In these cases, most of the infected women were asymptomatic and the duration of the insult had been likely too short to induce histological alterations. This cannot exclude molecular alterations in mitochondrial and oxidative pathways, due to the increased inflammatory environment reported in mothers positive to SARS-CoV-2. Indeed, we also reported evidence of increased immune activation profiles in SARS-CoV-2-positive subjects, with higher levels of cytokines and chemokines in placental tissue and maternal and funicular plasma [9].

In the symptomatic COVID-19 population, impaired mitochondrial dynamics were also found, with significantly decreased gene expressions of DNM1L and FIS1, both in- 
volved in mitochondrial fission, counterposed to no differences in the pro-fusion OPA1 expression. This is consistent with results on mtDNA and respiratory chain subunits expression, as reduced mitochondrial fission can lead to a decrease in the formation of healthy mitochondria [37]. In general, an overall shift toward less fission and more fusion events has been associated with cell senescence, higher ROS production and decreased mitochondrial activity $[53,54]$. Interestingly, Parone and colleagues reported that preventing mitochondrial fission in mammalian cells leads to a loss of mitochondrial DNA, impaired mitochondrial function and increased ROS levels, suggesting that mitochondrial fission is necessary for the maintenance of mitochondrial function and thereby to upkeep cellular homeostasis [55]. On the other hand, an increase in OPA1 has been suggested as a compensatory mechanism for increased mitochondrial content in preeclampsia, potentially by the stabilization of mitochondrial structures [56]. Indeed, overexpression of OPA1 protects from heart and brain ischemia and from ROS production [57].

\section{Strengths and Limitations of the Study}

All placentas analyzed in the present study were collected during the first period of the COVID-19 pandemic, between March and July 2020, when the pandemic's management and hospital organization were still being set up in Italy and all around the world. Nevertheless, the dedication of the doctors and midwives to this research project allowed the sample collection immediately after delivery. Moreover, the research group dedicated to the sample analysis was located very close to the delivery and surgery rooms, thus allowing immediate processing and proper conservation of samples.

Another strength of this work is represented by the well-characterized study population, which was composed of women with similar clinical characteristics in the cases and controls.

However, although we did not observe any differences between the cases and controls in the maternal pregestational BMI and other maternal characteristics, we cannot exclude that part of the reported differences between the infected and non-infected women may be due to the intrinsic characteristics of the population. Indeed, we previously reported that pregestational BMI can contribute to the severity of the disease, representing an inflammatory susceptibility factor [24]. However, only three severe cases were included in the present study, which suggests that alterations in the placental oxidative balance can also occur in non-severe, non-obese patients. Pharmacological treatments might also have impacted the placental inflammatory and oxidative features. Nevertheless, none of patients infected with SARS-CoV-2 in our population had received a cortisone therapy or specific anti-inflammatory treatments.

The investigation of mitochondrial and oxidative parameters in a larger population is also mandatory to draw any final conclusions. However, despite the low number of cases, this work lays the foundations for a deeper understanding of intrauterine processes occurring in mothers affected by COVID-19.

\section{Conclusions}

Altogether, our results suggest that changes in the placental mitochondrial features and oxidative balance in mothers infected by SARS-CoV-2 might be the result of an impaired intrauterine environment generated by the systemic viral effects, leading to a negative vicious circle involving COVID-19-enhanced systemic inflammation, which worsens placental oxidative stress and mitochondrial efficiency. The reported placental alterations are likely to make this fundamental organ more vulnerable and to provoke alterations in cell homeostasis, thereby raising the potential of further insults and possible long-term effects. 
Author Contributions: Conceptualization, C.M., V.M.S., G.M.A., C.N. and I.C.; formal analysis, C.M.; funding acquisition, C.M. and I.C.; investigation, G.M.A., S.C., A.S., F.L., C.T. and C.N.; methodology, C.M., V.M.S. and I.C.; project administration, C.M.; resources, C.M., V.M.S. and I.C.; supervision, C.M., V.M.S. and I.C.; validation, G.M.A. and A.S.; writing-original draft, C.M., G.M.A., A.S., F.L. and C.N.; writing-review and editing, C.M., V.M.S. and I.C. All authors have read and agreed to the published version of the manuscript.

Funding: This research received no external funding.

Institutional Review Board Statement: The study was conducted according to the guidelines of the Declaration of Helsinki and approved by the Institutional Ethics Committee (Comitato Etico Milano Area 1, protocol n 15408, 11 March 2020).

Informed Consent Statement: Informed consent was obtained from all subjects involved in the study.

Data Availability Statement: The data are contained within the article.

Acknowledgments: We are grateful to all the pregnant women that contributed to the study with their clinical and biological data. We thank the ethical committee for their contribution and rapid evaluation of the protocol of the study. Lastly, we are extremely thankful to all the Italian doctors and midwives that have provided an exceptional effort during the pandemic.

Conflicts of Interest: The authors declare no conflict of interest.

\section{References}

1. Martinez-Portilla, R.J.; Sotiriadis, A.; Chatzakis, C.; Torres-Torres, J.; Espino Y Sosa, S.; Sandoval-Mandujano, K.; CastroBernabe, D.A.; Medina-Jimenez, V.; Monarrez-Martin, J.C.; Figueras, F.; et al. Pregnant women with SARS-CoV-2 infection are at higher risk of death and pneumonia: Propensity score matched analysis of a nationwide prospective cohort (COV19Mx). Ultrasound Obstet. Gynecol. 2021, 57, 224-231. [CrossRef]

2. Dubey, P.; Reddy, S.Y.; Manuel, S.; Dwivedi, A.K. Maternal and neonatal characteristics and outcomes among COVID-19 infected women: An updated systematic review and meta- analysis. Eur. J. Obstet. Gynecol. Reprod. Biol. 2020, 252, 490-501. [CrossRef]

3. Jering, K.S.; Claggett, B.L.; Cunningham, J.W.; Rosenthal, N.; Vardeny, O.; Greene, M.F.; Solomon, S.D. Clinical Characteristics and Outcomes of Hospitalized Women Giving Birth With and Without COVID-19. JAMA Intern. Med. 2021, 181, 714-717. [CrossRef] [PubMed]

4. Knight, M.; Bunch, K.; Vousden, N.; Morris, E.; Simpson, N.; Gale, C.; O’Brien, P.; Quigley, M.; Brocklehurst, P.; Kurinczuk, J.J.; et al. Characteristics and outcomes of pregnant women admitted to hospital with confirmed SARS-CoV2 infection in UK: National population based cohort study. BMJ 2020, 369, m2107. [CrossRef]

5. Dumitriu, D.; Gyamfi-Bannerman, C. Understanding Risk for Newborns Born to SARS-CoV-2-Positive Mothers. JAMA 2021, 325, 2051-2052. [CrossRef]

6. Barker, D.J. The origins of the developmental origins theory. J Intern. Med. 2007, 261, 412-417. [CrossRef]

7. Kreis, N.N.; Ritter, A.; Louwen, F.; Yuan, J. A Message from the Human Placenta: Structural and Immunomodulatory Defense against SARS-CoV-2. Cells 2020, 9, 1777. [CrossRef] [PubMed]

8. Cribiù, F.M.; Erra, R.; Pugni, L.; Rubio-Perez, C.; Alonso, L.; Simonetti, S.; Croci, G.A.; Serna, G.; Ronchi, A.; Pietrasanta, C.; et al. Severe SARS-CoV-2 placenta infection can impact neonatal outcome in the absence of vertical transmission. J. Clin. Investig. 2021, 131, e145427. [CrossRef]

9. Fenizia, C.; Biasin, M.; Cetin, I.; Vergani, P.; Mileto, D.; Spinillo, A.; Gismondo, M.R.; Perotti, F.; Callegari, C.; Mancon, A.; et al. Analysis of SARS-CoV-2 vertical transmission during pregnancy. Nat. Commun. 2020, 11, 5128. [CrossRef]

10. Juan, J.; Gil, M.M.; Rong, Z.; Zhang, Y.; Yang, H.; Poon, L.C. Effect of coronavirus disease 2019 (COVID-19) on maternal, perinatal and neonatal outcome: Systematic review. Ultrasound Obstet. Gynecol. 2020, 56, 15-27. [CrossRef] [PubMed]

11. Mahyuddin, A.P.; Kanneganti, A.; Wong, J.J.L.; Dimri, P.S.; Su, L.L.; Biswas, A.; Illanes, S.E.; Mattar, C.N.Z.; Huang, R.Y.; Choolani, M. Mechanisms and evidence of vertical transmission of infections in pregnancy including SARS-CoV-2s. Prenat. Diagn. 2020, 40, 1655-1670. [CrossRef]

12. Patberg, E.T.; Adams, T.; Rekawek, P.; Vahanian, S.A.; Akerman, M.; Hernandez, A.; Rapkiewicz, A.V.; Ragolia, L.; Sicuranza, G.; Chavez, M.R.; et al. Coronavirus disease 2019 infection and placental histopathology in women delivering at term. Am. J. Obstet. Gynecol. 2021, 224, 382.e1-382.e18. [CrossRef]

13. Shanes, E.D.; Mithal, L.B.; Otero, S.; Azad, H.A.; Miller, E.S.; Goldstein, J.A. Placental pathology in COVID-19. Am. J. Clin. Pathol. 2020, 154, 23-32. [CrossRef]

14. Smithgall, M.C.; Liu-Jarin, X.; Hamele-Bena, D.; Cimic, A.; Mourad, M.; Debelenko, L.; Chen, X. Third-trimester placentas of severe acute respiratory syndrome coronavirus 2 (SARS-CoV-2)-positive women: Histomorphology, including viral immunohistochemistry and in-situ hybridization. Histopathology 2020, 77, 994-999. [CrossRef] 
15. Sharps, M.C.; Hayes, D.J.L.; Lee, S.; Zou, Z.; Brady, C.A.; Almoghrabi, Y.; Kerby, A.; Tamber, K.K.; Jones, C.J.; Adams Waldorf, K.M. A structured review of placental morphology and histopathological lesions associated with SARS-CoV-2 infection. Placenta 2020, 101, 13-29. [CrossRef]

16. Tasca, C.; Rossi, R.S.; Corti, S.; Anelli, G.M.; Savasi, V.; Brunetti, F.; Cardellicchio, M.; Caselli, E.; Tonello, C.; Vergani, P. Placental pathology in COVID-19 affected pregnant women: A prospective case-control study. Placenta 2021, 110, 9-15. [CrossRef]

17. Cetin, I.; Taricco, E.; Mandò, C.; Radaelli, T.; Boito, S.; Nuzzo, A.M.; Giussani, D.A. Fetal Oxygen and Glucose Consumption in Human Pregnancy Complicated by Fetal Growth Restriction. Hypertension 2020, 75, 748-754. [CrossRef]

18. Bianchi, C.; Taricco, E.; Cardellicchio, M.; Mandò, C.; Massari, M.; Savasi, V.; Cetin, I. The role of obesity and gestational diabetes on placental size and fetal oxygenation. Placenta 2021, 103, 59-63. [CrossRef] [PubMed]

19. Mandò, C.; Anelli, G.M.; Novielli, C.; Panina-Bordignon, P.; Massari, M.; Mazzocco, M.I.; Cetin, I. Impact of Obesity and Hyperglycemia on Placental Mitochondria. Oxid. Med. Cell. Longev. 2018, 2018, 2378189. [CrossRef]

20. Mandò, C.; Razini, P.; Novielli, C.; Anelli, G.M.; Belicchi, M.; Erratico, S.; Banfi, S.; Meregalli, M.; Tavelli, A.; Baccarin, M.; et al. Impaired Angiogenic Potential of Human Placental Mesenchymal Stromal Cells in Intrauterine Growth Restriction. Stem Cells Transl. Med. 2016, 5, 451-463. [CrossRef]

21. de Las Heras, N.; Martín Giménez, V.M.; Ferder, L.; Manucha, W.; Lahera, V. Implications of Oxidative Stress and Potential Role of Mitochondrial Dysfunction in COVID-19: Therapeutic Effects of Vitamin, D. Antioxidants 2020, 9, 897. [CrossRef]

22. Delgado-Roche, L.; Mesta, F. Oxidative Stress as Key Player in Severe Acute Respiratory Syndrome Coronavirus (SARS-CoV) Infection. Arch. Med. Res. 2020, 51, 384-387. [CrossRef] [PubMed]

23. Loffredo, L.; Violi, F. COVID-19 and cardiovascular injury: A role for oxidative stress and antioxidant treatment? Int. J. Cardiol. 2020, 312, 136. [CrossRef] [PubMed]

24. Scozzi, D.; Cano, M.; Ma, L.; Zhou, D.; Zhu, J.H.; O’Halloran, J.A.; Goss, C.; Rauseo, A.M.; Liu, Z.; Sahu, S.K.; et al. Circulating mitochondrial DNA is an early indicator of severe illness and mortality from COVID-19. JCI Insight 2021, 6, e143299. [CrossRef]

25. Savasi, V.M.; Parisi, F.; Patanè, L.; Ferrazzi, E.; Frigerio, L.; Pellegrino, A.; Spinillo, A.; Tateo, S.; Ottoboni, M.; Veronese, P.; et al. Clinical Findings and Disease Severity in Hospitalized Pregnant Women with Coronavirus Disease 2019 (COVID-19). Obstet Gynecol. 2020, 136, 252-258. [CrossRef] [PubMed]

26. de Santis, M.S.; Taricco, E.; Radaelli, T.; Spada, E.; Rigano, S.; Ferrazzi, E.; Milani, S.; Cetin, I. Growth of fetal lean mass and fetal fat mass in gestational diabetes. Ultrasound Obstet. Gynecol. 2010, 36, 328-337. [CrossRef]

27. Bertino, E.; Murru, P.; Bagna, R. Standard antropometrici neonatali nell'Italia nord- occidentale. River View Pediatr. 1999, 25, 899-906.

28. Novielli, C.; Anelli, G.M.; Lisso, F.; Marzorati, A.; Parrilla, B.; Oneta, M.; Savasi, V.M.; Cetin, I.; Mandò, C. Effects of $\alpha$-lipoic acid and myo-inositol supplementation on the oocyte environment of infertile obese women: A preliminary study. Reprod. Biol. 2020, 20, 541-546. [CrossRef]

29. Livak, K.J.; Schmittgen, T.D. Analysis of relative gene expression data using real-time quantitative PCR and the $2^{-\Delta \Delta C t}$ method. Methods 2001, 25, 402-408. [CrossRef]

30. Memon, N.; Bircsak, K.M.; Archer, F.; Gibson, C.J.; Ohman-Strickland, P.; Weinberger, B.I.; Parast, M.M.; Vetrano, A.M.; Aleksunes, L.M. Regional expression of the BCRP/ABCG2 transporter in term human placentas. Reprod. Toxicol. 2014, $43,72-77$. [CrossRef]

31. Johnson, L.J.; Azari, S.; Webb, A.; Zhang, X.; Gavrilin, M.A.; Marshall, J.M.; Rood, K.; Seveau, S. Human Placental Trophoblasts Infected by Listeria monocytogenes Undergo a Pro-Inflammatory Switch Associated with Poor Pregnancy Outcomes. Front. Immunol. 2021, 12, 709466. [CrossRef] [PubMed]

32. Amaral, M.S.; Goulart, E.; Caires-Júnior, L.C.; Morales-Vicente, D.A.; Soares-Schanoski, A.; Gomes, R.P.; Olberg, G.G.O.; Astray, R.M.; Kalil, J.E.; Zatz, M.; et al. Differential gene expression elicited by ZIKV infection in trophoblasts from congenital Zika syndrome discordant twins. PLoS Negl. Trop. Dis. 2020, 14, e0008424. [CrossRef] [PubMed]

33. Sarr, D.; Cooper, C.A.; Bracken, T.C.; Martinez-Uribe, O.; Nagy, T.; Moore, J.M. Oxidative Stress: A Potential Therapeutic Target in Placental Malaria. Immunohorizons 2017, 1, 29-41. [CrossRef]

34. Lutsenko, M.T.; Andrievskaya, I.A. Serotonin metabolism in the placenta in exacerbation of herpesvirus infection during pregnancy. Bull. Exp. Biol. Med. 2012, 154, 255-259. [CrossRef] [PubMed]

35. Kim, S.J.; Ahn, D.G.; Syed, G.H.; Siddiqui, A. The essential role of mitochondrial dynamics in antiviral immunity. Mitochondrion 2018, 41, 21-27. [CrossRef] [PubMed]

36. Sies, H. Oxidative stress: A concept in redox biology and medicine. Redox Biol. 2015, 4, 180-183. [CrossRef]

37. Holland, O.; Dekker Nitert, M.; Gallo, L.A.; Vejzovic, M.; Fisher, J.J.; Perkins, A.V. Review: Placental mitochondrial function and structure in gestational disorders. Placenta 2017, 54, 2-9. [CrossRef] [PubMed]

38. Hastie, R.; Lappas, M. The effect of pre-existing maternal obesity and diabetes on placental mitochondrial content and electron transport chain activity. Placenta 2014, 35, 673-683. [CrossRef]

39. Mele, J.; Muralimanoharan, S.; Maloyan, A.; Myatt, L. Impaired mitochondrial function in human placenta with increased maternal adiposity. Am. J. Physiol. Endocrinol. Metab. 2014, 307, E419-E425. [CrossRef]

40. Lee, H.C.; Wei, Y.H. Mitochondrial biogenesis and mitochondrial DNA maintenance of mammalian cells under oxidative stress Int. J. Biochem. Cell Biol. 2005, 37, 822-834. [CrossRef] [PubMed] 
41. Lu, M.; Sferruzzi-Perri, A.N. Placental mitochondrial function in response to gestational exposures. Placenta 2021, $104,124-137$. [CrossRef] [PubMed]

42. Sferruzzi-Perri, A.N.; Higgins, J.S.; Vaughan, O.R.; Murray, A.J.; Fowden, A.L. Placental mitochondria adapt developmentally and in response to hypoxia to support fetal growth. Proc. Natl. Acad. Sci. USA 2019, 116, 1621-1626. [CrossRef]

43. Anelli, G.M.; Cardellicchio, M.; Novielli, C.; Antonazzo, P.; Mazzocco, M.I.; Cetin, I.; Mandò, C. Mitochondrial content and hepcidin are increased in obese pregnant mothers. J. Matern. Fetal Neonatal Med. 2018, 31, 2388-2395. [CrossRef] [PubMed]

44. Novielli, C.; Mandò, C.; Tabano, S.; Anelli, G.M.; Fontana, L.; Antonazzo, P.; Miozzo, M.; Cetin, I. Mitochondrial DNA content and methylation in fetal cord blood of pregnancies with placental insufficiency. Placenta 2017, 55, 63-70. [CrossRef]

45. Zambon, M.; Mandò, C.; Lissoni, A.; Anelli, G.M.; Novielli, C.; Cardellicchio, M.; Leone, R.; Monari, M.N.; Massari, M.; Cetin, I.; et al. Inflammatory and Oxidative Responses in Pregnancies With Obesity and Periodontal Disease. Reprod. Sci. 2018, 25, 1474-1484. [CrossRef]

46. Mandò, C.; De Palma, C.; Stampalija, T.; Anelli, G.M.; Figus, M.; Novielli, C.; Parisi, F.; Clementi, E.; Ferrazzi, E.; Cetin, I. Placental mitochondrial content and function in intrauterine growth restriction and preeclampsia. Am. J. Physiol. Endocrinol. Metab. 2014, 306, E404-E413. [CrossRef]

47. Papageorghiou, A.T.; Deruelle, P.; Gunier, R.B.; Rauch, S.; García-May, P.K.; Mhatre, M.; Usman, M.A.; Abd-Elsalam, S.; Etuk, S.; Simmons, L.E.; et al. Preeclampsia and COVID-19: Results from the INTERCOVID prospective longitudinal study. Am. J. Obstet. Gynecol. 2021. [CrossRef] [PubMed]

48. Holland, O.J.; Cuffe, J.S.M.; Dekker Nitert, M.; Callaway, L.; Kwan Cheung, K.A.; Radenkovic, F.; Perkins, A.V. Placental mitochondrial adaptations in preeclampsia associated with progression to term delivery. Cell Death Dis. 2018, 9, 1150. [CrossRef] [PubMed]

49. Kotlyar, A.M.; Grechukhina, O.; Chen, A.; Popkhadze, S.; Grimshaw, A.; Tal, O.; Taylor, H.S.; Tal, R. Vertical transmission of coronavirus disease 2019: A systematic review and meta-analysis. Am. J. Obstet. Gynecol. 2021, 224, 35-53.e3. [CrossRef] [PubMed]

50. Seethy, A.A.; Singh, S.; Mukherjee, I.; Pethusamy, K.; Purkayastha, K.; Sharma, J.B.; Sharma, R.S.; Dhar, R.; Karmakar, S. Potential SARS-CoV-2 interactions with proteins involved in trophoblast functions-An in-silico study. Placenta 2021, 103, 141-151. [CrossRef]

51. Baergen, R.N.; Heller, D.S. Placental pathology in COVID-19 positive mothers: Preliminary findings. Pediatr. Dev. Pathol. 2020, 23, 177-180. [CrossRef]

52. Chen, S.; Liao, E.; Cao, D.; Gao, Y.; Sun, G.; Shao, Y. Clinical analysis of pregnant women with 2019 novel coronavirus pneumonia. J. Med. Virol. 2020, 92, 1556-1561. [CrossRef]

53. Kim, Y.Y.; Um, J.H.; Yoon, J.H.; Lee, D.Y.; Lee, Y.J.; Kim, D.H.; Park, J.I.; Yun, J. p53 regulates mitochondrial dynamics by inhibiting Drp1 translocation into mitochondria during cellular senescence. FASEB J. 2020, 34, 2451-2464. [CrossRef] [PubMed]

54. Lee, S.; Jeong, S.Y.; Lim, W.C.; Kim, S.; Park, Y.Y.; Sun, X.; Youle, R.J.; Cho, H. Mitochondrial fission and fusion mediators, hFis1 and OPA1, modulate cellular senescence. J. Biol. Chem. 2007, 282, 22977-22983. [CrossRef]

55. Parone, P.A.; Da Cruz, S.; Tondera, D.; Mattenberger, Y.; James, D.I.; Maechler, P.; Barja, F.; Martinou, J.C. Preventing mitochondrial fission impairs mitochondrial function and leads to loss of mitochondrial DNA. PLoS ONE 2008, 3, e3257. [CrossRef] [PubMed]

56. Vishnyakova, P.A.; Volodina, M.A.; Tarasova, N.V.; Marey, M.V.; Tsvirkun, D.V.; Vavina, O.V.; Khodzhaeva, Z.S.; Kan, N.E.; Menon, R.; Vysokikh, M.Y.; et al. Mitochondrial role in adaptive response to stress conditions in preeclampsia. Sci. Rep. 2016, 6, 32410. [CrossRef] [PubMed]

57. Varanita, T.; Soriano, M.E.; Romanello, V.; Zaglia, T.; Quintana-Cabrera, R.; Semenzato, M.; Menabò, R.; Costa, V.; Civiletto, G.; Pesce, P.; et al. The OPA1- dependent mitochondrial cristae remodeling pathway controls atrophic, apoptotic, and ischemic tissue damage. Cell Metab. 2015, 21, 834-844. [CrossRef] [PubMed] 